\title{
Assessment criteria and Program of Possibilities (P.o.P.): integration of new technologies in architecture and urban planning
}

\author{
A. van Timmeren ${ }^{1,2}$ \\ ${ }^{1}$ Climate Design \& Environment $(C D \& E)$, \\ Delft University of Technology (TUD), Faculty of Architecture, \\ The Netherlands \\ ${ }^{2}$ Atelier 2T, Haarlem, The Netherlands
}

\begin{abstract}
In the long term only closed cycles for processes and use of material could result in a permanent urban environment. The presented way of design tries to take the well-known metaphoric factor 20 improvement as a starting point: to preserve the essential flows and try to sustain the process to shape them towards closed cycles. The idea is to make urban development, mainly resulting in buildings and technical infrastructures, following to the (social) needs and goals, which form the basis of physical networks of the logistical chains, and not the other way around, like it can often be qualified today. In this way it will be possible to uncouple sustainable solutions from the existing paradigms, without the release of other relevant criteria for today's society. The main question is how to couple scientific research to architectural and urban design. Although often presented as such, this paper states that design cannot be qualified as scientific research. However, there are ways to interconnect scientific research and design: there is a reciprocal relationship. This paper introduces a new way to connect design and scientific research that can be used in urban development: Design by research is based on the introduction of a so-called 'Programme of Possibilities' (P.o.P.). The P.o.P. is mainly an essay of clues based on scientific research with a focus on redesign. This focus involves lateral thinking and creative alternatives that are not hindered by existing paradigms.
\end{abstract}

Keywords: Program of Possibilities, new sustainable technologies, spatial criteria, environmental criteria, social criteria. 


\section{Introduction}

There is a need to compare sustainable concepts and accompanying structures as alternatives for conventional sanitation and energy generation with respect to a greater number of aspects than the ones being indicated by the existing paradigms and dominant actors in urban planning. This is the background for the presented research. The basis is formed by urban planning based on 'interconnection', as well as waste management in general, and on closure of the essential cycles (energy, nutrients, carbon and water) inside urban settlements, or as close to them as possible.

The research has been commissioned by the Delft University of Technology (TUD) in The Netherlands as part of the CD\&E - Climate Design \& Environment - research) to investigate and develop sustainable decentralised sanitation, energy and reuse technologies. The aim is to research the spatial, social and environment related consequences of the implementation of these technologies, and to define the conditions within society, with emphasis on urban planning and building [1].

\section{Sustainable planning and development}

\subsection{Interpretations of the Factor 20 environmental-efficiency improvement}

If we want to give the third world as much prosperity as ourselves, alike the points of departure of the Brundtland committee or the 'equity principle', this will, according to the Ehrlich, Speth and Commoner formulae [2] imply the need for the changing society (incl. building) to reduce the use of 'environmental space' of its consumption goods to $5 \%$ of the actual use. If one talks about sustainability, one can't escape from talking about paradigm-shifts. Three knowledge systems can be distinguished which play a part: a system of natural scientific explanations, a system of societal explanations and a system of individual value judgments. They can be encapsulated as 'technology', 'culture' (behaviour, needs) and 'structure' (institutions, economics, etc.). The formulae of Ehrlich and Speth can however be seen as one of two interpretations of the commonly subscribed 'Brundtland definition' of Sustainable Development [3]. Main characteristic of this interpretation is the assumption of a certain limitation the ecological system puts to our acting. This outlook is called 'the ecological position' [4]. It claims that "nature is orderly and self-organising, that ecological science gives directives what the self-organisation of nature looks like, and that society should fit up to these directives". The shortcoming of this interpretation is the absolutation of the sustainable ambition, assuming the need to put the available 'environmental space' as basis for all policies. As long as ethic issues like (non) existence are concerned, the extent in which a norm or goal can be fulfilled, dependently the extent in which it will function at the expense of other norms and goals, can not be 'absoluted' into the (final) definition of (non) sustainability of an operation. Even 'all-autarkic' concepts obviously aren't 'allsustainable'. Apart from that it isn't clear at all time what sustainability implies 
for acting, because of the indistinctness and the changing character of the relationship of the different criteria concerning this sustainability.

The second group of interpretations of the Brundtland definition emphasises the word 'development' within this definition, which according to this view indicates that it shouldn't involve pointed out environmental boundaries that can't be exceeded but a 'search direction'. Sustainable development in this case is seen as a dynamic process, a boundless perspective instead of a limited 'environmental space'. This outlook is called 'the process or interaction approach'. The consequence of this approach is not the maximalisation of the environmental interest, but the optimalisation of these interests in relation with other interests. However there is a so-called 'prescript-problem': no norms are being indicated. It admits the different interpretations and goals of the involved actors and recommendations therefore can only be accomplished in case of a rather arbitrary "actuality-definition". Besides, this 'interaction approach' is based on network theories and arises out of the recognition of many uncertainties that adhere to the ambition of sustainable development.

Both interpretations of sustainable development however touch upon the same 'prescript-problem', which due to the lack of clear parameters to quantify sustainability makes that certain vagueness exists concerning the needed measures. Even definitions, like the Brundtland definition of sustainable development are so open that it's relatively simple for people, institutes and governments to avoid measures or to claim sustainability through lateral measures which sustainability can be argued.

The two different approaches sometimes are being indicated as 'weak' and 'strong' sustainability. The difference specialises in the question to what extent sustainable development on a natural scientific basis can be established and operationalised. The 'strong' interpretation states that this is possible while the 'weak' interpretation says that too many technical and scientifical uncertainties exist. In the Brundtland report the importance of democratic procedures is pointed out [3]. Sustainable development due to this report cannot be enforced from above but should be realised via a bottom-up process. If one handles the dynamic interpretation of the Brundtland definition of 'sustainability' this means that the process side should be emphasised instead of the formulation and handling of rigid (static) limits.

Therefore the creation of space for initiatives and/or change after realisation is equal or even more important than (only) participation during the process of planning. In addition to the possibility of other types of use of (agricultural) grounds (urban agriculture), the link to agriculture may not only lead to a structurally different infrastructure (aboveground and underground), but also to different country planning as a whole, when applied on a larger scale.

\subsection{Planning policies}

Lately in several scientific publications and policy planning documents more attention is being paid to the malfunctioning of the different urban policies of today and the additional spatial investments at (eu)regional scale. The Dutch Scientific board for governmental policies states that "these systems only 
facilitate standard solutions". Apart from that, the actual policies tend to lead to long procedures and delays, which due to its relative slow launching also tend to difficulties to follow the needs of the changing society. Not to mention steering it. In the Netherlands therefore recent policies put more emphasis at so called 'urban networks' instead of cities or conglomerates. However, in practice the mutual administrative and policy adaptation on this scale appears to be inflexible and rarely leading to fathomed planning, not to mention social participation. The board concludes also a need to come to better differentiation in planning together with a closer cooperation of local, (eu)regional and national governments. A more (eu)regional oriented planning in this case should be the answer to the ever-vanishing division of city and countryside and thus could make an end to what sometimes is called the 'scale paradox' in urban planning. In case of execution of more differentiated and decentralised planning processes, the Dutch Scientific board for governmental policies forgets the fact that these planning processes often are stuck to the existing 'body' of physical (technical) infrastructure and accompanying administrative, mostly not very flexible institutions and standards, which altogether reduce further possibilities of participation and change. If one wants to come to urban planning that gears to the ever faster changing society this barrier has to be broken. An additional problem is the fundamentally different nature of environmental/ecological and economical interests. The environment related problems often are diffuse. The problems are being derivated to a larger area or are being shifted to the future (generations). However, economical interests mostly are more concentrated. This applies for instance in case of central facilities that are being considered as 'general (needed) goods', like the energy-supply. Due to stockrelated privatization, (part of) the benefit deserves to parties that run a relatively small (investment) risk with regard to the costs of these projects. In this case the specific sectoral interest can differ quite strongly from the conventional general economical interest. Apart from that, one-sided representation of interests can slow up (sustainable) renewal. New ideas that don't cope with present interests will be considered less seriously. This process is improving in some sectors, due to the started privatization and therefore the need for 'redesign', to cope with the additional competition. Redesign in this case is (only) the re-examination of interests and plans (developments) towards a more sustainable direction. The actually needed phase of 'rethinking', the taking care of ongoing integration of coming economical and environmental interests, still are a long way away from these, mostly conventional parties. This (still) appears to be the assignment for governments and science.

\subsection{Urban planning and sustainability}

For sustainable concepts we can discern two future paths: the ones that comply with the principles of 'the scale economy' and concepts that follow 'the economies of scale'. One can distinguish three models for the development and supposedly successful application of technologies: the 'quasi-evolutionary model', the 'collective problem definition' and the 'network theory'. The accompanying so-called 'selection-environment' is being based on scientific 
technological factors, economical factors and social cultural \& political factors. The present development of use of sustainable technologies can be described as processes in accordance with the quasi-evolutionary model in combination with the network theory. The historical development and the scaling-up of technologies based on prevailing paradigms determine its quasi-evolutionary nature. Besides of that there is a matter of a small but strong network with only a few, mostly dominant 'actors' for each of the different circuits or 'flows' (water, energy, and waste).

The necessary threshold to a sustainable society according to the Brundtland definition [3] is being hindered by these separated circuits: new sustainable technologies are continually being developed in all sectors, but the assimilation by society often falters. The main goal actually should be the third recognised model: the collective problem definition by all more or less important 'actors', by a broadening of the 'process networks'.

\section{Development of new sustainable technologies}

\subsection{Specialization versus integration strategies}

Within the environmental research tradition the care for water- and energy saving through reduction of demand, efficiency improvements and use of renewable sources always has been obvious. At the end of the last century a strong segregation amongst different 'actors', including universities and research institutes was found. Besides of that, the field of (inter)national energy policies also still can be characterised by a certain institutional fragmentation. This results in some clear-cut contrasts between: different sectors of the energysupply, the energy supply side (orienting for expansion of capacities) versus the demand side (orienting for energy management and -reduction), and the policies of the different energy- and environment connected departments or ministries.

Most research projects concerning the so-called 'essential flows' (energy and sanitation, i.e. waste and water) don't attempt to extract themselves from their sectarian policy field, making horizontal interconnections. The scientific and strategic compartmentalization is being legitimised in calling it 'specialisations'. The different 'specialists' subsequently maintain their sectarian way of thinking. The interactions between different specialises, forms of (technical) infrastructure and their future manifestation are in scientific perspective therefore still uncultivated fields. The only sciences that come closer to this sectarianexceeding way of thinking are planning and economy, although these too have some restrictions. Planning for instance and building in general put emphasis on forms of (most non-technical) infrastructure that have a clear physical component. More to sustainability related themes like dematerialisation (i.e. not immaterialization) don't come up. In economic sciences different forms of infrastructure are drawn in analysis, but this is being realised only in cost/income comparisons. Problem stays here the general difficulty to express 'merits' in terms of money. 
Only just after the introduction of the concept 'sustainable development' by the Brundtland commission, policy formulation cautiously started to relate energy-saving and later water-saving on the one hand, and the improvement of environmental quality on the other hand. The last decade(s) of the $20^{\text {th }}$ century one can see improvement concerning consciousness and many publications indicating that the saying "Think global, act local" should be the basis of new solutions to make the society more sustainable. However, also that this is exactly the problem towards the consciousness-raising of today's society. The relation between personal acting and the (global) environmental effects in the short and the long term is for many difficult to visualise. Key factor therefore will be this visualisation of the effects of private acting of people. A lot of times these publications translate the former to a call for visualisation of acting on a scale nearer to the users, like in the seventies/eighties Schumacher did [5]. But this doesn't inevitably mean that the solutions should be decentralized, or implemented at the smallest scale.

\subsection{Rethinking development networks}

There is a common consensus in society about the necessity of fundamental facilities for meeting the most fundamental needs in the own living environment, viz. "Maintenance", the so-called primary necessity of life. The availability of energy and food, including clean drinking water, and the removal of waste are parts of it. It is no use trying to introduce sustainability measures that harm this fundamental need. New (decentralized) technologies are being developed constantly in all fields, but the assimilation by society often is faltering.

Besides of the former stated ruling 'central paradigms' and 'dominant actors' another cause lays in the 'separate circuits' within the developing technology [6]. The solution could be found in a broadening of the development-networks around technology. Another possibility might be the improvement of social involvement through information, documentation and successful examples. However, this isn't as simple as stated. If a technology is still young, the social implications are barely known and if the social implications are known, the technology is indebted in such a way that it is impossible to adapt it to the desires of the different actors. This is called the 'Collingridge-dilemma' [7]. To resolve this dilemma it is necessary to reflect fundamentally the societal conditions of the needed approach to implement this sustainable technology. The three main movements concerning the question if this is possible can be summarised as technological-, economical- and social-constructivist determinism. The first group of people think that (sustainable) technologies develop autonomously out of them, and therefore can't be influenced by society. The second group state that technological innovations can only be successful if they are profitable, while the third group state that there needs to be harmony between all actors about the course of the development of (sustainable) technology. The first two perspectives can be named unshakeable, as far as the sustainable technologies, technical infrastructure and buildings concerning the energy- and (waste)water flows are concerned. Therefore the solutions towards real sustainable concepts should be found within social-constructivist adaptations. 
Therefore it is of importance to distinguish design levels for tuning parties involved to the design and change processes. Particularly the direction into which decision-making and development become directive is of importance. The social, geographical and/or political (decision) structures are decisive, although they may vary strongly as regards their physical sizes. Moreover, many environmental effects are cross-border phenomena. With respect to the spatial demarcations, the fact that the "eco-device balance" (the restricted spatial area considered) may be taken in a literal sense to a larger or a smaller extent plays a part. The basis is whether or not external sources are used along with internal sources. There are also time scales at work: a specific amount of time has scale consequences (distance) for flows. This holds particularly for sanitation flows. Decreasing the rate of transport can restrict the spatial scale of a flow (and/or problem). This may however produce new problems in the restricted spatial area. In general, one could say that the specific location and the accompanying parties involved determine to what extent internal sources will be used only, or both internal and external sources will be used, and to what extent the solutions will be connected to the time scales.

\subsection{General assessment criteria for new sustainable technologies and concepts}

The Dutch Ecopolis strategy [8] has been taken as a starting point for the formulation of the relevant conditions for new alternatives. The strategy distinguishes three points of view: flows, areas and actors. These can be connected to respectively environmental conditions, spatial conditions and social (user-related) conditions or criteria. The environment or flow-related criteria distinguished are:

- a maximum of health guarantees, hygiene and safety (free from threats);

- security of utilities and consistency;

- a minimum or an optimum of added raw materials;

- a minimum of pollution of soil, air, ground area and surface water;

- closing cycles as much as possible;

- a minimum of energy use;

- resilience to sabotage/incorrect use;

- future value (flexibility and uniformity).

Spatial conditions with respect to the built-up environment are often linked to Vitruvius's "Utilitas, Firmitas, Venustas". This research focuses on the utilities and their essential networks. Besides this, a scale level is considered larger than that of the building (and the context) only. Consequently, the main spatial or area related criteria are: flexibility, complexity, identity and strategy. Or, in more detail: 
- $\quad$ optimizing collection and transport;

- minimizing or optimizing use of materials;

- $\quad$ adaptability and extendibility;

- $\quad$ screening off against sabotage and vandalism;

- $\quad$ optimizing use of (ground) surface area;

- $\quad$ fitting into the living environment;

- accessibility of parties involved;

- aesthetic quality.

The spatial criteria and environmental criteria have a strong relation with the parties involved. Consequently, dilemmas occur quite easily; for example, the criteria of "screening off" and "accessibility" are a dilemma in their interrelation.

Early participation and the correct knowledge (socially constructivist view), or the attempt to reduce the lack of knowledge among users, is of decisive importance for commitment to the issue. Therefore in the presented research, the users' interest are put first when alternatives or solutions are offered. The social criteria for the successful implementation and use of alternative systems or techniques have been drawn up from a user perspective. They are:

- equal or more comfort;

- similar costs;

- $\quad$ equal or more ease of use;

- empowerment, i.e. independence of specialized institutions and compulsory networks ;

- $\quad$ image and transparency: aesthetic quality and visibility of solutions.

Redesigning large parts of the primary process in a top-down manner is necessary for the implementation of the substantial structural and sustainable improvements. However, to achieve optimal conditions for innovation and technology development and acceptance this should be combined with 'bottom up' local initiatives. Within the alternating process of incremental and structural innovation the incremental innovation should shift more to solutions that follow the principle of 'subsidiarity' of the European Community (matters should be handled by the lowest competent authority ).

\subsection{Participation and interaction: the Program of Possibilities (P.o.P.)}

In the democratic triangle formed by the three main groups of parties involved, viz. government, market and citizens, the relation between the first and the third is changing at the moment, because of the withdrawing government and the accompanying liberalization processes. The former relationship between State and citizen, to be characterized as linear (a modern society, fragmented with respect to power), has been transformed into alternating networks of 
collaborative structures. The result is a changed margin for the co-ordination and participation processes of (residential) areas. This leads to a larger interest to involve users and other "relevant" parties into the planning processes as early as possible, or, in other words, to aim for more commitment. There is always a basis for collaboration with the various parties involved in a process, irrespective of the individual, sometimes conflicting aims. The choice for specific interested parties or their involvement is decisive for the eventual development process. In order to have as many of all the relevant parties involved participating, groups (of partners) are selected normatively or according to their "power" and influence in the residential area.

The theme of "design" or the group of "designers" cannot be classified into the categories established in this research (according to [9]: (1) owners, (2) financial institutions, (3) action groups, clients/users, (4) consumers' organizations, (5) trade unions, employees, (6) commercial organizations, (7) competitors, (8) suppliers, (9) governments, and (10) political organizations. Nevertheless, there is an important task for designers, viz. mapping people's demands and wishes, and supporting and visualizing the concrete common aims.

The other, often dominant parties involved should realize that the involvement of inhabitants/users goes further than just the change (design, construction). It should be a balanced concept that is interconnected with surrounding projects, in a structure that supports flexible and continuous change processes, is open, and is continuously capable of absorbing corrections through permanent reflection (and learning), also called 'place-making'. Also because of the possible learning processes, optimal communication and a maximum of involvement are vital when making comparative assessments in the preferably pluricentric decision-making.

Generally taken The Netherlands has two models of decision-making for the (technical) infrastructure and the accompanying systems/layers: the "model of decision", or "referee model", that places the problem of difficult decisionmaking among opposing individuals, interest groups and lower authorities; and the "interaction model", also know as "coaching model". The latter starts from the position that it is the decision makers that cause the possible problems.

In order to really contribute to quality improvement, all "partners" within the process should declare their willingness to integrate the systems to be used. Within the scope of sustainability, the "coaching model" or "interaction model" has the best chances. The advantage is that people can be prevented from working up to a solution in the shape of a specific infrastructural project too quickly, without sufficiently thinking about the relationship between the suprastructure (what do we want) and the buildings and infrastructure (how can we best accomplish this goal). A sound method of decision-making following this interaction model is the so-called "co-production": recognizing the existence of mutual dependence between the various parties and interests. The model can be made more effective by putting in new (possibly interactive) information technologies. In a digital (Internet) environment, an unambiguous working environment can easily be introduced for unhampered use by the various partners. 
In such a complex interaction and integration process, it is crucial to appoint a so-called "leading actor". It is natural to appoint the designer for this purpose.

The approach of integrating social learning processes and "place making" which has been applied in the main case study within the presented research is known as the "architect model".

In such a way of working, it is important how to deal with the various parties concerned and their interaction and learning processes. The pluricentric method of interaction combined with the concept op "open design" offers the best perspectives, and is particularly suitable because of the current "specialists' society" and the many parallel dynamic processes playing a part: it is an interactive learning process, in which participants may only develop and tune (adjust) their goals during the process. The emphasis is on directing the transformation process and developing alternatives while the process itself is going on. This is why the so-called 'Programme of Possibilities' has been introduced. It can be considered as an assistant during the search for potential (new) sustainable concepts and technologies within the process of open design with the different stakeholders. Besides, this Programme of Possibilities, or "P.o.P.", is used in this research to formulate conclusions made in the theoretical and analytical parts of the research solution-oriented. So the main solutions and trends are described, discerning seven different scale-levels (building, cluster/block, neighbourhood, district, city\& hinterland, poly-city network and region + ), five different stages (initiative, design, realisation, use and end-of-life), four essential flows (energy, drinking water, wastewater, solid waste) and the ten previously stated different stakeholders. In some publications a similar concept to the P.o.P. has been presented: the 'Essay of Clues' [10]. In the presented research, the P.o.P. is used as a basis for the development and realisation process of different alternatives and possible solutions in the case study Lanxmeer, Culemborg (The Netherlands) [1].

\section{Conclusion}

One could state that the infrastructure of the essential flows, due to its 'pathdependent', long term character and the existence of a limited number of dominant actors per network or flow, is determinative to what degree a project will or can be sustainable. Especially the waste(water) infrastructure and the energy infrastructure can be characterised by transported flows which are not drawn up out of ongoing 'ecologisation' and dematerialisation but out of efficiency in central management and other economical factors. From the point of view of sustainability the technical infrastructure and with it urban development as a whole therefore seems to be insufficiently efficient. As a conclusion, it can be stated that differentiation and flexibility in the area of town and country planning are preconditions for being able to anticipate uncertainties in the long term. By pluricentric development based on the method of 'open design' with use of a solution oriented P.o.P., or Programme of Possibilities the process of introducing new, real alternative and innovative sustainable solutions can be achieved. Additionally, it is easier to anticipate dynamic developments 
that are characteristic of today's society. It might help to prevent the process of urbanization and the infrastructural transport and distribution systems of the essential flows from developing in separate ways.

\section{References}

[1] Timmeren, A. van Autonomie \& Heteronomie. Integratie en verduurzaming van essentiële stromen in de gebouwde omgeving. $\mathrm{PhD}$ thesis. Delft University of Technology. Eburon Academical Publishers. Delft. 2006.

[2] Ehrlich, P. and Ehrlich, A. The population explosion, Hutchinson, London, United Kingdom. 1990

[3] World Commission on Environment and Development (WCED) Our common future. Oxford University Press, pp4, New York. USA. 1987.

[4] Korthals, M. et al Wetenschapsleer; Filosofisch en maatschappelijk perspectief op de natuur- en sociaal-culturele wetenschappen. Boom Meppel/Amsterdam. The Netherlands. 1989.

[5] Schumacher, E.F. Small is beautiful, Blond \& Briggs, London, UK. 1973.

[6] Vergragt, Ph.J. Naar een ecologische technologie, Technology Assessment and Sustainability, Faculty of Technology, Policy \& Management, Delft University of Technology, Delft. The Netherlands. 1992.

[7] Collingridge, D. The social control of technology, Frances Pinter, London. United Kingdom. 1980.

[8] Tjallingii, S.P. Ecological conditions; strategies and structures in environmental planning. IBN Scientific Contributions 2. IBN-DLO, Wageningen. The Netherlands.1996.

[9] Freeman, R.E. Strategic Management: A stakeholder approach, Pitman, Boston. United States of America. 1994.

[10] McDonough, W. Cradle to cradle. Remaking the way we make things, North Point Press, New York. United States of America. 2002. 